\title{
2016-2017: UN BIENIO ACIAGO PARA LA REPÚBLICA DE COREA
}

Juan José Ramírez Bonilla

El Colegio de México

Leonel Murillo Muñoz

Universidad del Valle de México

Para la República de Corea (Corea del Sur o Corea), los catorce meses transcurridos entre el 1 de octubre de 2016 y el 30 de noviembre de 2017 estuvieron marcados por fuertes tensiones domésticas e internacionales, en los campos de la política y de la economía. En el campo de la política doméstica, los medios de comunicación independientes desafiaron al gobierno de la presidenta Park Geun-hye, sacando a la luz las redes de influencia tejidas desde la oficina de la presidencia que paralizaron el sistema de justicia, beneficiaron a la señora Choi Soonsil y permitieron extorsionar a un número considerable de empresas coreanas. Ante las evidencias de corrupción y de la participación de la consejera personal de la presidenta Park en asuntos de Estado, la población coreana se volcó a las calles y logró su destitución. La crisis política allanó el camino para una elección anticipada y para un giro en la política doméstica tendiente a sanear las estructuras institucionales; la primera parte de nuestro trabajo está abocada al análisis de esta crisis política.

En la segunda parte, concentramos nuestra atención en el análisis de la política exterior coreana en el nuevo contexto creado por los ensayos nucleares y balísticos del gobierno de la República Popular Democrática de Corea, así como por la retórica y la política agresivas del presidente de Estados Unidos de América contra el régimen de Pyongyang; en ese marco, 
destacamos tanto las relaciones intercoreanas mediadas por la política exterior estadounidense como el papel de los gobiernos chino y japonés en tanto actores regionales destacados.

Finalmente, en la tercera parte, estudiamos las vicisitudes de la economía coreana: en primer término, ponemos de realce la doble sincronía de las dinámicas de las economías global y coreana; por un lado, destacamos la estrecha relación entre las fluctuaciones cíclicas de ambas, y por el otro, ponemos el acento en la entrada de la economía coreana en una fase de crecimiento lento, similar al de la economía global. En segundo lugar, llamamos la atención sobre las peculiaridades de la inserción de la economía coreana en la economía global, para mostrar que aquélla ha consolidado vínculos con las economías de Asia-Pacífico en particular, y de Asia en general, y que el mercado estadounidense tiene ahora una importancia de tercer orden; en consecuencia, ante las amenazas de la administración Trump sobre la renegociación del Acuerdo de Libre Comercio Estados Unidos-Corea, las autoridades coreanas están dispuestas a renunciar a dicho acuerdo.

\section{EL SISTEMA POLÍTICO COREANO EN CRISIS}

Durante el último trimestre de 2016, el sistema político coreano experimentó la crisis política más profunda desde el inicio de su democratización, y sus repercusiones han marcado el desempeño del mismo durante enero-octubre de 2017. La crisis ha puesto en evidencia las dificultades experimentadas por cualquier sociedad para sustituir los mecanismos clientelares y la corrupción inherente a ellos, con pautas institucionales transparentes orientadas a limitar al máximo tanto el desvío de fondos públicos como las gratificaciones otorgadas a funcionarios públicos por los servicios que están obligados a prestar.

Fuera de Corea, la destitución de la presidenta Park Geun-hye eclipsó los efectos de la crisis sobre el sistema judicial, sobre empresas de la talla de Samsung y Hyundai, así como sobre el partido de la presidenta. En términos temporales, la crisis se desarrolló en tres fases: la primera estuvo marcada por la incubación de la crisis y se extendió desde 2015, hasta el 25 de octubre de 2016, cuando la presidenta Park aceptó públicamente sus vínculos personales con la señora Choi Soon-sil. El desarrollo de la segunda etapa de la crisis fue determinado por el creciente descontento de la población (expresado en manifestaciones 
públicas, masivas y semanales, en la plaza Gwanghwamun, frente al ayuntamiento de Seúl) y culminó el 10 de marzo de 2017, cuando la Corte Constitucional de Corea ratificó la decisión de la Asamblea Nacional de destituir a la presidenta (9 de diciembre de 2016). La tercera fase estuvo caracterizada por la preparación y la realización de la elección presidencial ganada por Moon Jae-in el 9 de mayo de 2017.

\section{La incubación de la crisis: los fantasmas de los padres alcanzan a los hijos}

Cuatro actores, dos directos —el expresidente Park Chung-hee ${ }^{1}$ y su consejero privado Choi Tae-min ${ }^{2}$ y dos indirectos — sus respectivas hijas, la presidenta Park Geun-hye y la señora Choi Soon-sil—, estuvieron en el centro del drama político.

La relación entre Park Chung-hee y Choi Tae-min se remonta a 1974; el 15 de agosto de ese año, Yuk Young-soo, esposa de Park Chung-hee, murió en un atentado contra este último. Poco después, Choi Tae-min se presentó ante Park Geun-hye para anunciarle la aparición de su madre en sueños y la encomienda de cuidarla (Leung, 2016). Las notas periodísticas indican que, a partir de entonces, fue considerado consejero personal de Park Chung-hee; y devino amigo íntimo de su hija;

entre otras cosas, Park Chung-hee le encomendó a Choi Tae-min promover su campaña 'Nueva Comunidad', un movimiento ultranacionalista que combinaba proyectos de infraestructura con captación de fondos. Se cree que Choi Tae-min empleó sus extensas pero cuestionables credenciales religiosas para garantizar el éxito de la campaña, estableciendo numerosas organizaciones religiosas para colectar fondos; se supone que grandes proporciones de dichos fondos fueron desviadas a cuentas personales y a muchas empresas inmobiliarias ahora propiedad de Choi Soon-sil y sus familiares (Fendos, 2017).

Durante la crisis política de 2016, la prensa coreana recuperó informaciones sobre los nexos personales de la presidenta Park Geun-hye y la señora Choi Tae-min; por ejemplo,

\footnotetext{
${ }^{1}$ Nació el 14 de noviembre de 1917 y murió asesinado el 26 de octubre de 1979; llegó al poder tras un golpe de Estado, realizado por una junta militar encabezada por él, en mayo de 1961; en 1963, fue electo presidente de la República de Corea y se mantuvo en el cargo hasta el momento de su muerte; es considerado el iniciador de la modernización económica de Corea (Wikipedia, "Park Chung-hee").

${ }^{2}$ Nació el 5 de mayo de 1912 y murió el 1 de mayo de 1994. Fue un monje budista, después se convirtió al catolicismo y más tarde fundó la Iglesia de la Vida Eterna, que mezclaba elementos cristianos, budistas y animistas (Wikipedia, "Choi Tae-min").
} 
señalaba que, en 2007, cuando Park Geun-hye buscaba la nominación de su partido como candidata a la presidencia de la República de Corea, fue acusada por un miembro de su propio partido de recibir una casa como gratificación por haber otorgado un lucrativo contrato de construcción, mientras fungía como presidenta de la Universidad Yeongnam. De acuerdo con los informes periodísticos, su detractor fue sometido a juicio por "haber violado la ley sobre financiamiento de campañas" y la señora Choi-Soon-sil participó como testigo clave de la defensa de la señora Park Geun-hye (Fendos, 2017).

En todo caso, el escándalo que causó la destitución de la presidenta se desarrolló siguiendo una trayectoria sinuosa. En octubre de 2015, Jung Woon-ho, director general de la empresa de cosméticos Nature Republic, fue arrestado por apuestas ilegales y evasión de impuestos. Jung Woon-ho contrató los servicios legales de Choi Yu-jeong, un antiguo juez, a quien le pago al menos cinco millones de dólares, con el fin de obtener la condonación de la pena impuesta. Todo hubiera pasado desapercibido, de no ser por la agresión física de Jung Woon-ho contra su abogado, cuando éste se negó a devolverle una parte de los honorarios recibidos, después de ser negada la condonación de la pena.

El monto de los honorarios pagados puso en alerta a las autoridades judiciales y la fiscalía profundizó la investigación, confirmando el pago de sobornos a abogados y jueces; entre los primeros, figuró Hong Man-pyo, quien había participado en la defensa de Jung Woon-ho por una acusación similar de apuestas ilegales, en 2012. Según la prensa coreana, Hong Man-pyo, fiscal en ejercicio hasta 2011, utilizó su influencia sobre investigadores y fiscales que habían sido sus alumnos, para obtener el desistimiento de las autoridades en el caso de las apuestas ilegales de Jung Woon-ho de 2012. Hasta aquí, las redes de tráfico de influencias eran tejidas dentro del sistema judicial y al margen de la rama ejecutiva del gobierno.

Sin embargo, las investigaciones mostraron la asociación de Hong Man-pyo con Woo Byung-woo, quien también había ejercido como fiscal antes de ser nombrado secretario de asuntos civiles del gabinete de la presidenta Park Geun-hye. Woo Byung-woo, en junio de 2016, estuvo envuelto en dos escándalos: el primero por tráfico de influencias para evitar a su hijo los rigores del servicio militar, mediante su transferencia de un cuartel militar a una estación de la policía militar antes del periodo reglamentario; el segundo por la venta por 
encima del precio de mercado de un terreno propiedad de una cuñada, por parte de una empresa productora de juegos computacionales; las investigaciones mostraron que Jin Kyung-joon, subordinado de Woo Byung-woo en la fiscalía, había recibido sobornos de esa compañía; no obstante, tanto la compañía como Jin Kyung-joon fueron exonerados por "falta de evidencias."

En este punto, actores civiles y medios de información intervinieron en el desarrollo de los acontecimientos; un grupo civil solicitó una investigación sobre los posibles vínculos de Woo con la empresa computacional, pero la solicitud nunca fue respondida. La prensa, por otro lado, concentró su atención sobre las fundaciones Mir y K-Sport; por primera vez surgió el nombre de Choi Soon-sil como un canal entre la Casa Azul y "muchas corporaciones que hicieron misteriosas donaciones a las fundaciones." Woo apareció como un posible vínculo entre Choi y la Casa Azul. Sin embargo, en agosto de 2016, la reacción oficial fue, por un lado, "lanzar una feroz defensa de Woo, criticando los medios por tratar de socavar la oficina de la presidencia, 'difundiendo rumores falsos' para crear una 'administración vegetativa"” (Fendos, 2017); por el otro, la oficina de la presidencia inició una campaña de desprestigio del editor del periódico Chosun Ilbo, acusándolo, a través de un miembro del Parlamento, de estar involucrado en una red de corrupción financiada por el ex director general de los astilleros Daewoo y provocando su renuncia a la dirección del periódico.

Las presiones se extendieron contra otros medios de comunicación y los equipos responsables de las noticias fueron reorganizados, cuando no suprimidos, provocando protestas de los sindicatos de periodistas. A principios de octubre, el periódico Hankyoreh y el canal de noticias JTBC, subsidiario del periódico Joong Ang Ilbo, prosiguieron las investigaciones sobre Mir y K-Sport. En un primer momento, obtuvieron el testimonio de un exempleado de las fundaciones sobre los nexos estrechos de Choi Soon-sil con los directivos de las mismas.

El 18 de octubre, la filtración de noticias adquirió un nuevo cariz, cuando JTBC anunció haber encontrado la tableta personal de Choi Soon-sil, comprometiéndose a revelar progresivamente el contenido de la misma. Los temas del tráfico de influencias y de los sobornos quedaron atrás y la intervención de Choi Soon-sil en asuntos exclusivos de la oficina de la presidencia devino el foco de interés: 
JTBC concentró su atención en mostrar cómo los discursos de la presidenta Park parecían haber sido editados directamente en la tableta, contradiciendo los borradores originales aportados por exmiembros de la oficina de la presidencia. Algunos de estos exempleados declararon tener conocimiento de la participación de Choi, añadiendo combustible al fuego (Fendos, 2017).

E1 24 de octubre, JTBC entregó la tableta de Choi a los fiscales y éstos declararon "no ver ninguna razón para investigar a Choi, ni saber dónde se encontraba para interrogarla”. La señora, no obstante, ese mismo día recurrió al periódico Segye Ilb para negar haber usado la tableta en cuestión. El 25, la presidenta presentó sus primeras disculpas públicas, limitándose a decir que "algunas veces se apoyaba en Choi en tiempos dificiles". La presidenta aceptó su responsabilidad al involucrar en los asuntos de Estado a la señora Choi y desató la crisis que habría de costarle el puesto.

Al inicio de la crisis, el tráfico de influencias en el sistema judicial, la subordinación del mismo a la presidencia y las presiones de ésta sobre los medios de comunicación fueron utilizados para intentar ahogar el escándalo. Gracias a la tenacidad del periódico Hankyoreh y del canal de televisión JTBC, el público tuvo acceso a la información detallada del caso y salió a las calles para exigir e imponer, mediante la movilización, el funcionamiento de las instituciones políticas.

\section{La modernidad democrática bajo el peso de las tradiciones}

Durante la fase de gestación de la crisis, el conflicto opuso los medios de comunicación con el sistema judicial, en un primer momento, y en un segundo, con el tándem sistema judicialpresidencia; cuando fueron del domino público las evidencias acerca de las redes interpersonales de la presidenta Park sobre las cuales descansaban los mecanismos para extorsionar a las empresas, los términos y la dinámica de la oposición cambiaron: los términos fundamentales de la contradicción fueron la población descontenta con la gestión patrimonialista del gobierno y la presidenta Park; los medios de comunicación actuaron como factor modulador de las movilizaciones, conforme ponían al alcance de la población nuevos detalles del escándalo.

E1 26 de octubre, JTBC mostró las conexiones virtuales mediante las cuales Choi recibía informaciones de Kim Han-soo, empleado de la oficina de la presidencia y familiar político 
de Choi. Mientras tanto, en Alemania, la policía anunciaba investigaciones sobre los negocios ilícitos de Choi en territorio alemán y reporteros coreanos visitaban su casa, para constatar que había sido apresuradamente abandonada. Las investigaciones posteriores demostrarían tanto las comunicaciones de Choi con sus socios en Corea como el conocimiento de la físcalía sobre su paradero en Europa. Pese a ello, cuando Choi regresó a Seúl, el 30 de octubre, la fiscalía no hizo nada para detenerla; la prensa tuvo conocimiento de su llegada gracias a las fotografías tomadas por un pasajero y, ante la evidencia, la fiscalía terminó arrestándola el $1^{\circ}$ de octubre.

Ante la inacción de una fiscalía bajo sospecha de querer ahogar el escándalo, el $1^{\circ} \mathrm{de}$ octubre la población protestó públicamente frente a las oficinas de la Fiscalía Suprema, iniciando una escalada: mientras más informaciones sobre los nexos de Choi con la presidenta eran develadas por los medios de comunicación, mayores eran las concentraciones públicas en que se exigía la renuncia de la presidenta Park. Así, del 5 de noviembre de 2016 al 7 de enero de 2017, cada sábado la población se concentró en la plaza Gwanghwamun, frente al ayuntamiento de Seúl, y en las plazas de las principales ciudades para exigir la renuncia de la presidenta Park, primero, y después del 9 de diciembre de 2016, la remoción inmediata de la misma.

El movimiento de protesta fue conocido como la Revolución de las Velas y sus momentos climáticos fueron:

- El 3 de diciembre, 2.3 millones de personas protestaron en las calles de las principales ciudades del país, exigiendo la renuncia de la presidenta.

- El 10 de diciembre, más de un millón de protestantes vitorearon la remoción de la presidenta Park; la víspera, la Asamblea Nacional decidió quitar a la presidenta, con 234 votos a favor y 56 en contra; las funciones de la presidenta fueron suspendidas durante un plazo de seis meses, en espera de la decisión de la Corte Constitucional sobre la destitución.

- El 17 de diciembre, por primera vez, los manifestantes a favor de la presidenta rebasaron el millón de personas y superaron el número de protestantes contra la presidenta; a partir de entonces, la dinámica en las calles estuvo marcada por protestas y antiprotestas. 
- El 21 de enero de 2017, las protestas adquirieron un nuevo cariz: las investigaciones sobre la señora Choi sacaron a la luz los nexos financieros ilegales con Lee Jaeyong, vicepresidente y heredero de Samsung; durante la semana precedente, una corte había desechado la solicitud para su arresto; la demanda sobre la remoción inmediata de la presidenta fue acompañada por la exigencia del arresto del heredero de Samsung.

- El 18 de febrero, las protestas celebraron el arresto del vicepresidente de Samsung el día anterior y exigieron a la Asamblea Nacional una rápida decisión sobre el despido de la presidenta.

- El 11 de marzo, Seúl fue literalmente dividida espacialmente por la policía para evitar el choque de las manifestaciones en contra y a favor de la presidenta, después de que, el viernes 10 de marzo, la Corte Constitucional de Corea ratificara, con una votación de 8 a favor, 0 en contra y 1 abstención, la destitución de la presidenta. (Wikipedia, "Impeachment of Park Geun-hye").

Como se ha señalado, las investigaciones sobre los vínculos entre la presidenta Park y la señora Choi sacaron a la luz las contribuciones ilegales de algunas de las grandes empresas coreanas a las instituciones controladas por ellas o a ellas directamente. Así, el vicepresidente de Samsung fue arrestado el 17 de febrero por "pagar sobornos equivalentes a 30 millones de libras esterlinas a la entonces presidenta Park Geun-hye y a su amiga cercana Choi Soonsil para obtener los favores gubernamentales" (Fifield, 2017); de acuerdo con los informes de prensa, después del arresto, la empresa reconoció "haber hecho contribuciones a dos fundaciones sin fines de lucro supuestamente controladas por Choi y su empresa con base en Alemania". Bajo el cargo de sobornos y otras cuatro violaciones, los fiscales solicitaron una sentencia de doce años de cárcel para Lee Jae-yong; sin embargo, el 25 de agosto de 2017, fue sentenciado a cinco años de cárcel y, en el momento de escribir estas líneas, espera en prisión el resultado del recurso de apelación (Boxall, 2017).

Los informes de prensa son enfáticos con los resultados de las investigaciones sobre los nexos de la presidenta Park y la señora Choi con empresas coreanas:

Park fue acusada de ayudar a la asistente presidencial no oficial Choi Soon-sil en un esquema de extorsión. Se presume que más de 50 empresas fueron presionadas para hacer donaciones 
valoradas en 69 millones de dólares, para fundaciones deportivas respaldadas por Choi y creadas después de la fusión de Samsung; dichas fundaciones luego fueron utilizadas para obtener ganancias financieras personales, garantizando, a cambio, la aprobación de acuerdos controvertidos [favorables para las empresas] (Boxall, 2017).

La crisis política coreana de 2016-2017 ha demostrado que las reformas democráticas formales son una condición necesaria, pero no suficiente, para lograr una democratización efectiva de cualquier sistema político. Así, la soberanía de la población puede estar inscrita en la constitución política; pero sin mecanismos efectivos para garantizar la vigilancia y el control de la población sobre sus representantes, existe el riesgo de que la administración gubernamental sea ejercida como un patrimonio personal de los funcionarios públicos.

En Corea, la libertad de prensa estuvo a punto de ser letra muerta; a pesar de las presiones gubernamentales para callar los medios de comunicación, un número restringido de éstos ejercieron ese derecho para realizar una doble labor: por un lado, de vigilancia sobre los funcionarios y los representantes públicos y, por el otro, de información pública sobre el desempeño de los mismos; la población, mediante la movilización en las calles, impuso su derecho a destituir, cuando menos, a los funcionarios más visibles en los escándalos de corrupción.

Ahora bien, la cultura política basada en el ejercicio patrimonialista de la administración pública no desaparece con reformas institucionales formales y determina la necesidad de contar con mecanismos permanentes de vigilancia y de control de la sociedad sobre sus representantes; en el caso coreano, los medios de información han ejercido esa función de vigilancia y las movilizaciones en la calle han impuesto el control social sobre los representantes; sin embargo, esta experiencia tiene costos elevados y, aunque efectiva, es ineficiente, ya que los medios pueden ocuparse de una vigilancia puntual, pero no estructural, y la población no puede mantenerse movilizada permanentemente para hacer valer el principio de la soberanía. Parafraseando aquella consigna del 68 francés, la solución de los problemas de la democracia efectiva exigen el poder de la imaginación para idear y poner en práctica mecanismos sociales de vigilancia y control sobre todas las instancias de gestión pública. 


\section{La elección presidencial de 2017 y el movimiento pendular del electorado}

Los autores del informe sobre Corea para el Anuario Asia Pacífico 2017 (León Manríquez y Cárdenas Barajas, 2017) pusieron de realce el giro político conservador de la política doméstica coreana, marcado por las elecciones de Lee Myung-bak (2008-2013) y de Park Geun-hye (2013-2017) como presidentes de la República de Corea. Como indicadores del giro conservador, León-Manríquez y Cárdenas Barajas proponían:

- Los resultados de la elección presidencial de diciembre de 2012, con una participación de $75.8 \%$ de los electores registrados y con $51.6 \%$ de los votos para la presidenta Park Geun-hye.

- La polarización del voto en diferentes dimensiones:

○ En la regional, el partido conservador acaparó "el voto de las provincias del suroeste del país y de aquellas regiones históricamente beneficiadas por la inversión industrial del gobierno".

○ En la generacional, Park Geun-hye "contó con una amplia base de apoyo entre los segmentos de edad media y avanzada.

○ En la ocupacional, Park Geun-hye "fue apoyada por agricultores, grandes compañías y elites económicas".

Durante la elección del 9 de mayo de 2017, los escándalos que provocaron la destitución de la presidenta Park trastocaron el escenario político: en primer término, la tasa de participación electoral fue de 77.2\%; se trata de la proporción más elevada de lo que va del siglo XXI y se inscribe en la tendencia hacia un incremento progresivo de la participación electoral, iniciada en 2007, cuando la tasa de participación apenas registró 63\%. Queda por ver si esta tendencia se mantiene en el futuro y si expresa un interés creciente de la población coreana en los asuntos políticos.

Segundo, Moon Jae-in, candidato del Partido Democrático, ganó las elecciones con 41.1\% de los votos; considerado progresista, su triunfo marcó el movimiento pendular del electorado.

Tercero, el partido que llevó a la señora Park a la presidencia en 2012 se dividió en dos facciones: quienes la sostuvieron durante la crisis formaron el Partido Corea Libertad y 
apoyaron la candidatura de Hong Jun-pyo, quien terminó acumulando $24 \%$ de los votos; otro grupo se alineó con quienes exigían la destitución de la presidenta y formó el partido Bareun para sostener a Yoo Seung-min como candidato a la presidencia y alcanzar 6.8\% de los votos.

Cuarto, desde la elección presidencial de 1992, el sistema político coreano había funcionado sobre la base de dos partidos dominantes; en la elección de 2017, el voto fue fragmentado y disperso en cinco formaciones políticas: Partido Democrático (41.1\%), Partido Libertad de Corea (24.0\%), Partido del Pueblo (21.4\%), Bareun (6.8\%) y Partido de la Justicia (6.2\%). La pregunta obligada consiste en saber si los resultados de ésta serán la base para un sistema de partidos más abierto a la competencia o si solo se trata del impacto de los escándalos sobre la clase política. En todo caso, la última palabra sobre el futuro del sistema de partidos corresponderá al electorado.

Quinto, en términos territoriales, es posible constatar un cambio drástico entre las elecciones de 2012 y 2017; en la gráfica 1 es evidente el amplio retroceso del partido heredero del legado de la presidenta Park y el progreso del Partido Democrático. Los feudos conservadores del sureste del país todavía fueron dominados por el Partido Libertad de Corea; sin embargo, es observable la pérdida de influencia en Ulsan y Busan; esta última ciudad es un importante centro industrial y principal puerto marítimo del país.

Sexto, en términos de los grupos fundamentales de la población, también hubo un cambio significativo. De acuerdo con una encuesta de salida, levantada durante el día de la elección, la población entre 19 y 59 años de edad votó mayoritariamente por Moon Jae-in; en la gráfica 2, la línea azul está ubicada en el 41.1\% de los votos alcanzado por dicho candidato y muestra que la población entre 19 y 49 años votó en su favor en proporciones muy por encima de ese valor medio; el grupo de 50-59 años también votó mayoritariamente en favor del candidato vencedor; sin embargo, los diferenciales con respecto a los candidatos de los lugares segundo y tercero fueron reducidos. El desempeño electoral de Hong Jun-pyo, candidato del partido de la presidenta Park, sólo fue destacado entre los electores con más de 60 años de edad; entre el grupo de 50-59 años, obtuvo una proporción que superaba el 24.1\% de los votos obtenidos en el recuento final, pero no fue suficiente para obtener la mayoría relativa en este grupo de edades; el reverso de la medalla del éxito de Moon Jae-in entre los 
electores de 19 a 49 años es el escaso eco prestado a Hong Jun-pyo: 8.6, 0.0 y $11.5 \%$ de los grupos de 19 a 29 , de 30 a 39 y de 40 a 49 años.

GRÁFICA 1. Resultados electorales en 2012 y 2017
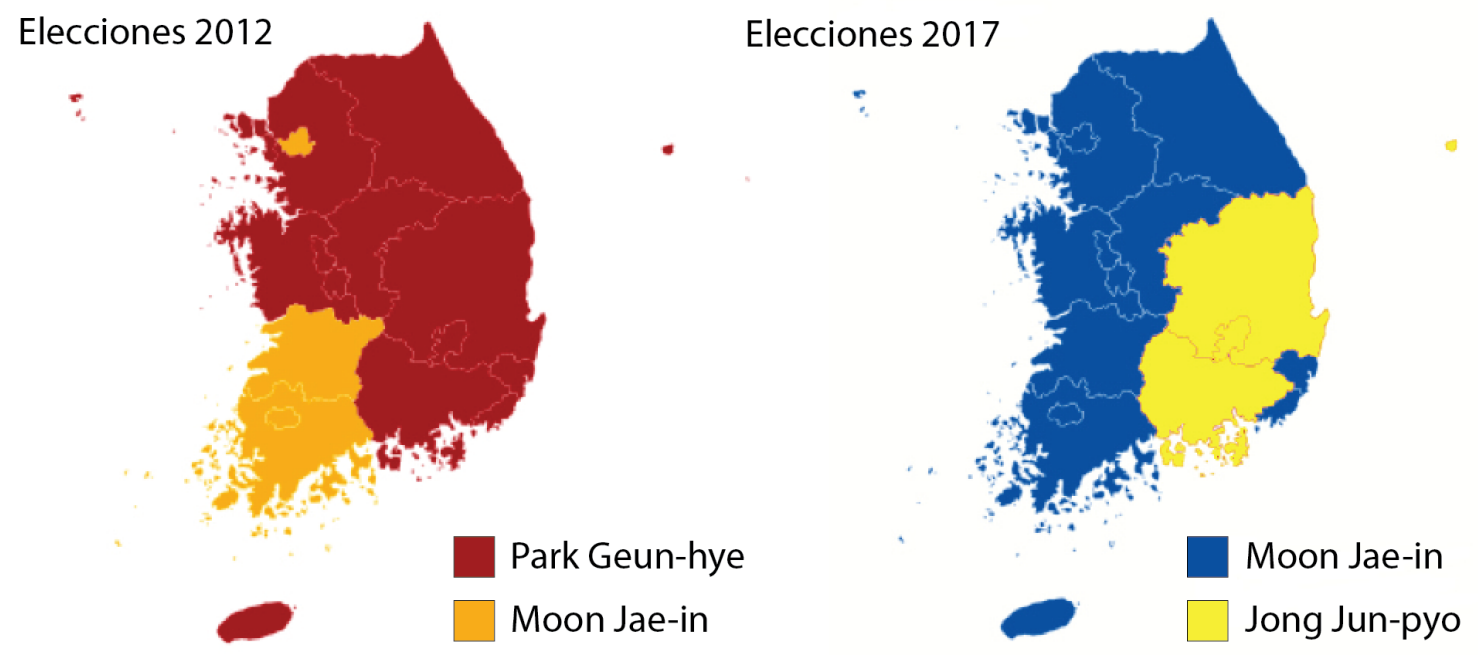

Fuente: Wikipedia, Elections in South Korea

GRÁFICA 2. Distribución de votos por candidatos y por grupos de edad de los electores

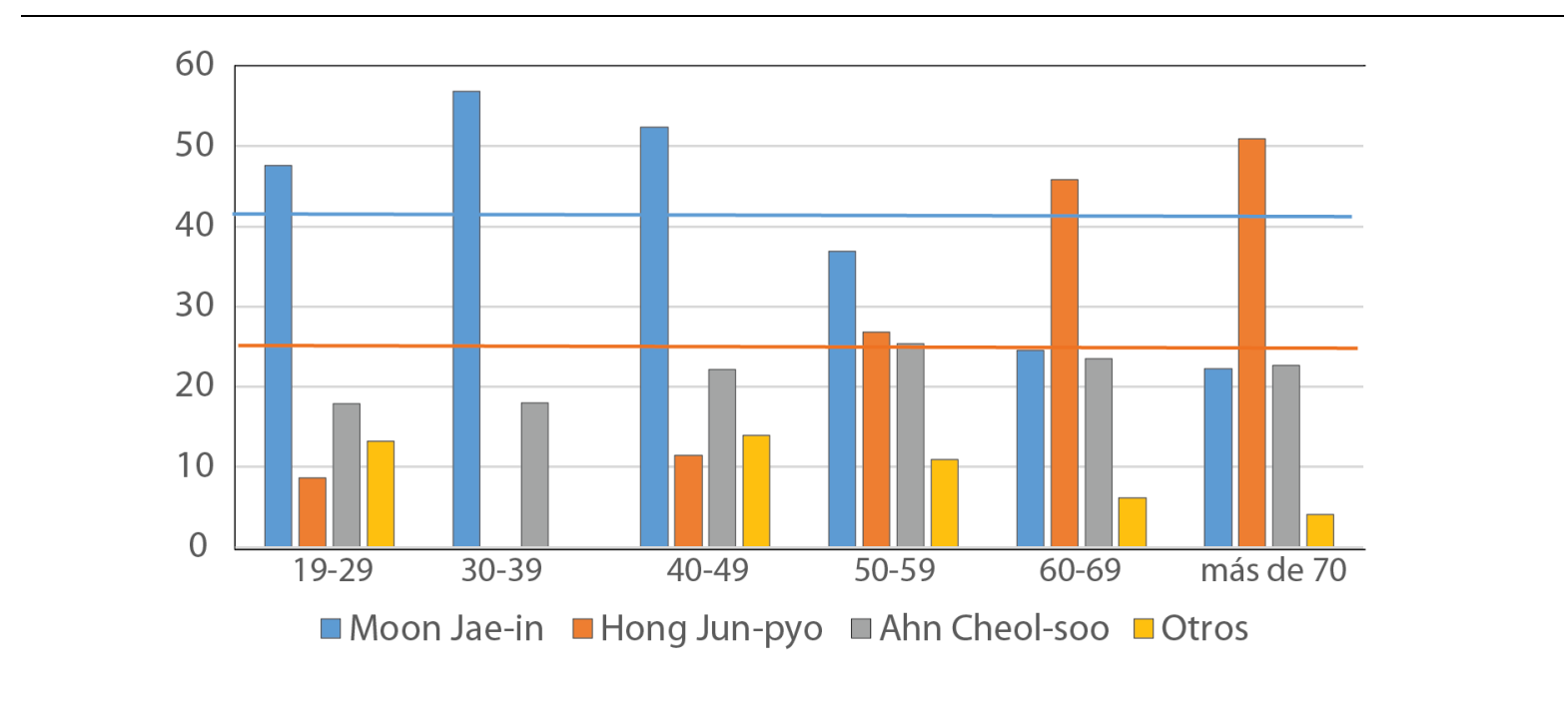

FUENTE: Elaboración propia, con información de National Election Comission, $<$ http://info.nec.go.kr/>. 
En relación con el sexo de los votantes, la gráfica 3 muestra que el voto femenino favoreció a Moon Jae-in, mientras que el masculino benefició a Hong Jun-pyo; en el caso de Ahn Cheol-soo, el resultado fue más o menos equilibrado.

Es posible concluir que el resultado de la elección fue determinado por factores subjetivos y objetivos; entre los subjetivos, es necesario resaltar el profundo impacto del escándalo político sobre amplios sectores de la población; entre los objetivos, destaca la decisión, por un lado, de los grupos jóvenes y maduros de la población, y por otro, de las mujeres para votar emitiendo un mandato para corregir los vicios puestos en evidencia por los escándalos políticos. Corea vuelve a comprobar en la práctica que los movimientos sociales progresistas son impulsados por los jóvenes y por las mujeres; este rasgo de la Revolución de las Velas permite abrigar esperanzas de que el movimiento pendular de los resultados electorales marque el inicio de una nueva etapa en el mejoramiento de la calidad de la democracia coreana.

GRÁFICA 3. Distribución de los votos por candidato y por sexo de los electores

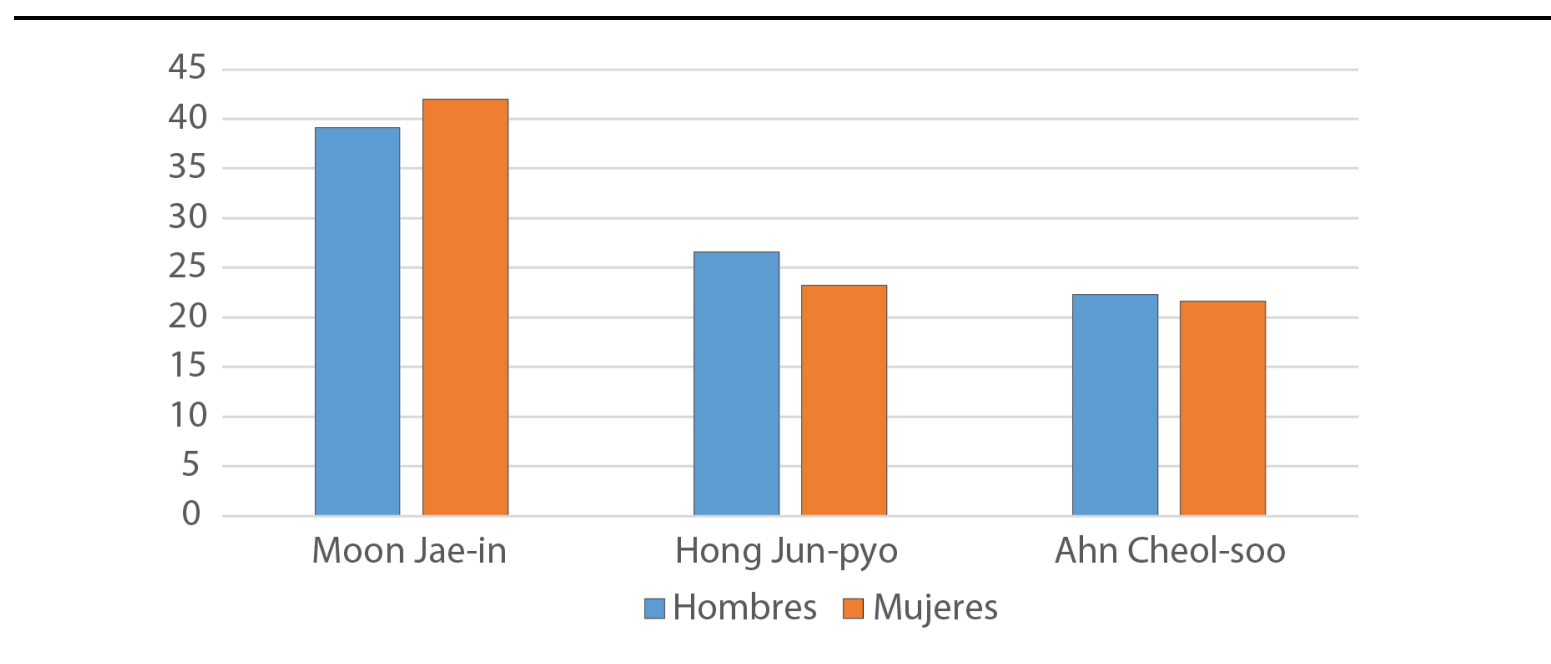

FUENTE: Elaboración propia, con información de National Election Comission, <http://info.nec.go.kr/>. 


\section{LA POLÍTICA EXTERIOR DE COREA DEL SUR}

\section{Y LA CRISIS NORCOREANA}

La península de Corea ha dado mucho de qué hablar en los últimos meses debido al aumento en las tensiones internacionales, principalmente entre Estados Unidos y Corea del Norte; estas tensiones han provocado un distanciamiento entre las dos Coreas debido a la presencia militar de Estados Unidos en la región. El gobierno surcoreano ha tenido un año difícil; como vimos, experimentó una de las crisis internas más fuertes de su historia; con la destitución de la expresidenta Park Geun-hye, la crisis afectó al gobierno y a la economía surcoreana; en materia de política exterior, el cambio de administración estadounidense, el programa nuclear de Pyongyang, las políticas de Naciones Unidas en contra del régimen de Kim Jong-un y la participación directa de Japón y China en el conflicto han presionado al Ministerio de Asuntos Exteriores surcoreano en materia de seguridad colectiva e integración económica; estos factores ha complicado la reunificación de las Coreas, tema de suma importancia, ${ }^{3}$ pues se encuentra plasmado en el articulo $4^{\circ}$ de la Constitución de Corea del Sur (Government of Korea, 1987).

Para entender el ejercicio de la política exterior surcoreana y las relaciones entre los principales actores involucrados en el conflicto peninsular, analizaremos los siguientes factores: 1) La influencia de la presencia militar de Estados Unidos de América en la región Asia-Pacifico sobre la unificación de la península de Corea. 2) Los cambios de la política exterior de Corea del Sur hacia Corea del Norte, según la política exterior de Estados Unidos hacia los gobiernos de uno y otros países. 3) Las participaciones de Japón y de China como actores regionales y el ejercicio de sus políticas exteriores en torno a la crisis norcoreana.

\section{La división de una nación; los estragos de la Guerra Fría}

En la segunda mitad del siglo Xx, durante la Guerra Fría, existió una tendencia clara en la política exterior de los gobiernos con respecto a la política exterior de las dos potencias hegemónicas de la época, Estados Unidos y la Unión Soviética; una de estas políticas fue la

\footnotetext{
${ }^{3}$ La división de Corea es una de las medidas polémicas de las Naciones Unidas; tuvo un carácter geopolítico muy marcado, tomando la península como un país buffer para ambos bandos; esto trajo como consecuencia la división social de una nación.
} 
aprobación de la división provisional de la península de Corea, resultante de la política de contención del socialismo aplicada por el gobierno de Estados Unidos, según los términos acordados en la Conferencia de Postdam; en dicha conferencia, los gobiernos de las potencias aliadas acordaron aceptar la rendición de las facciones en conflicto dentro de la península, así como la división provisional de la península de Corea, tomando como referencia el paralelo $38^{\circ}$, para evitar que el conflicto continuara y se intensificara; por otro lado, la división garantizaba la contención del socialismo en el norte. En 1947 la Organización de la Naciones Unidas (ONU) aprobó el establecimiento de un gobierno provisional y democrático en la parte sur del territorio (Barry, 2012).

Después de la división, las tensiones entre ambos bandos aumentaron debido al apoyo de las potencias dominantes a las dos facciones en conflicto; este intervencionismo en los asuntos internos de la península provocó una guerra civil a los pocos años (Carlos $\mathrm{R}$. Fernández Liesa, 2013).

A partir de este periodo, la política exterior del gobierno de Corea del Sur con respecto al gobierno de Corea del Norte ha estado determinada en su mayor parte por las acciones de los gobiernos de Estados Unidos y de China con respecto a la política exterior de Corea del Norte. Como indica Yoon Jong-Han, las relaciones entre Corea del Norte y Corea del Sur tienden a tener un distanciamiento en los diálogos de paz y un aumento en las tensiones cuando los gobiernos de Estados Unidos y/o de China intervienen en el conflicto, o cuando éstos endurecen sus políticas contra el gobierno de Corea de Norte. En este análisis destaca de una manera muy detallada cuánto afectan las políticas de terceros Estados en los esfuerzos de reunificación de la península con base en un sistema de variables; llama la atención la importancia de la administración estadounidense en la política exterior norcoreana: las administraciones demócratas tienden a tener una mejor relación con el gobierno de Corea del Norte, lo cual ayuda a crear mejores espacios de diálogo entre el norte y el sur de la península; por el contrario, las administraciones republicanas tienden a tener una política mucho más rígida, lo cual reduce los espacios de diálogo y aumenta de manera considerable las tensiones en la zona (Yoon, 2011). 
La nueva administración estadounidense, la militarización de la región y los cambios en la política exterior de Corea del Sur

Durante el último año, las relaciones entre Corea del sur y Corea del Norte han dado un giro debido a las maniobras militares y pruebas nucleares en la zona por parte del ejército de Corea del Norte. Aunado a esto, el cambio de administración en Estados Unidos y las sanciones económicas por parte de la ONU han distanciado a ambos gobiernos en los espacios para los diálogos de paz.

Los gobiernos de Corea del Sur y de Estados Unidos han tenido un mayor acercamiento debido a las pruebas nucleares realizadas por el ejército de Corea del Norte. Las primeras declaraciones de Trump, como presidente electo de Estados Unidos, con respecto a la presencia de tropas en países aliados, resultaron desfavorables para Seúl; estas declaraciones hacían hincapié en lo poco redituable, para las finanzas internas estadounidenses, de mantener tropas en el extranjero; en respuesta, el gobierno de Corea del Sur firmó un pacto preliminar de inteligencia con Japón, frente la amenaza de Corea del Norte; los diálogos entre ambos gobiernos comenzaron desde 2012 y tomaron fuerza gracias a las tensiones recientes (REUTERS Staff, 2017); por otro lado, la respuesta del gobierno surcoreano al estadounidense fue externar su preocupación por la cooperación bilateral de ambos países en materia de seguridad y, a pesar de declaraciones previas, el presidente electo Donald Trump reiteró el apoyo de Estados Unidos: "éste permanecería firme junto con Corea del Sur y así continuarlos con el apoyo para mantener la paz y la seguridad de Asia Pacifico" dijo el mandatario el 10 de noviembre de 2016 (El Mundo, noviembre de 2016).

Después del aumento de las sanciones económicas aplicadas a Corea del Norte en respuesta al programa nuclear de Pyongyang y a las declaraciones posteriores de Kim Jongun sobre el endurecimiento de las medidas de autodefensa (El Mundo, diciembre de 2106), los gobiernos de Estados Unidos, Corea de Sur y Japón ratificaron conjuntamente las sanciones; sólo unos días después, Seúl dio luz verde al proyecto de construcción de los sumergibles Chang Bogo-III, como una alternativa a la incertidumbre generada con el cambio 
de administración norteamericana y, por otro lado, como una forma de prevenir posibles agresiones por parte de Pyongyang (RT, 2016). ${ }^{4}$

Una de las primeras acciones de la nueva administración norteamericana, en coordinación con el gobierno de Seúl, fue un ensayo de evacuación ante el aumento de la amenaza nuclear, en donde militares y sus familias realizaron un ejercicio de prueba en caso de un ataque nuclear o biológico por parte de Pyongyang; días después, el gobierno de Corea del Norte lanzó un misil balístico; en respuesta, los gobiernos de Estados Unidos, Japón y Corea solicitaron una consulta urgente al Consejo de Seguridad de las Naciones Unidas. La reunión tuvo lugar un día después del lanzamiento del misil; el Consejo de Seguridad condenó drásticamente las acciones de Pyongyang y amenazó con imponer nuevas "medidas significativas contra el régimen" (Villar, 2017); sin embargo, Estados Unidos expresó su descontento y argumentó sobre lo poco eficiente de aplicar un marco de acción basado en simples palabras.

La relación diplomática entre Corea del Sur y Estados Unidos continúa hasta la fecha en el mismo tenor de estira y afloja constante. Después de que el gobierno de Corea del Norte realizara un lanzamiento fallido el 18 de abril, explotó en costas norcoreanas casi inmediatamente después de ser lanzado (BBC Mundo, 2017), Donald Trump arremetió contra el gobierno de Corea del Sur por el costo de un sistema antimisiles ${ }^{5}$ de mil millones de dólares, junto con la amenaza de eliminar el acuerdo de libre comercio existente entre las dos naciones. La respuesta del gobierno de Corea del Sur fue casi inmediata: "El gobierno de Corea del Sur continuará con la postura inicial"; ${ }^{6}$ el sistema antimisiles THAAD fue colocado con la colaboración de los gobiernos surcoreano y norteamericano en territorio surcoreano; este sistema sirve para proteger a los ciudadanos de la región de la amenaza de Corea de Norte y, a su vez, representa un punto estratégico cerca de la República Popular China, lo cual

\footnotetext{
${ }^{4}$ Según un estudio de Yoon, (2011) el endurecimiento de las políticas internacionales hacia Corea del Norte nunca es favorable para los diálogos de paz; a pesar de esto, las políticas puestas en práctica a lo largo de 2017 estuvieron (en su mayoría) enfocadas al endurecimiento de las medidas contra el gobierno de Corea del Norte. Cabe señalar a China como un actor en la región que se opone al endurecimiento de las sanciones económicas contra el régimen de Kim Jong-un.

${ }^{5}$ El sistema Terminal High Altitude Area Defense (THAAD).

${ }^{6}$ Los acuerdos militares entre Corea del Sur y Estados Unidos están plasmados en un tratado de defensa mutua; con referencia al sistema (THAAD), este acuerdo fue firmado por militares de EU y Corea del Sur en julio de 2016; según este acuerdo, "EU asume el costo del despliegue del sistema (THAAT)" (Boykoff, 2017).
} 
constituye un problema para el gobierno de Corea de Sur y su política exterior con China. Evidentemente el gobierno de China está en contra del despliegue de este sistema cerca de sus fronteras.

El ultimo acercamiento entre los gobiernos de Corea del Sur y Estados Unidos tuvo lugar en noviembre de 2017 después de acercamientos entre los jefes de Estado de ambos países, en torno a la renegociación del Acuerdo de Libre Comercio y del Acuerdo de Defensa Mutua. En los primeros días del mes de noviembre el presidente Donald Trump realizó una visita de Estado a Corea del Sur. ${ }^{7}$ En ella, el mandatario trató con su homólogo, entre otras cosas, sobre el Acuerdo de Libre Comercio, el cual calificó de "infructuoso y no muy bueno para Estados Unidos" (YonHap News Agency, 2017). El gobierno de Corea del Sur formuló su política en relación con el Acuerdo de Libre Comercio a través del jefe de negociadores del Ministerio de Asuntos Exteriores de Corea del Sur, Kim Hyun-chong, mediante un comunicado en el cual el funcionario coreano pedía la autorización al gobierno surcoreano para terminar el acuerdo de libre comercio en caso de ser necesario ${ }^{8}$ el comunicado dejaba en otro apartado los temas de seguridad colectiva, los cuales habían tenido un despliegue importante en los primeros días del mes de noviembre, con el sobrevuelo de aviones sobre Corea del Norte; en este ejercicio militar participaron los gobiernos de Estados Unidos, Corea del Sur y Japón (YonHap News Agency, 2017).

Por otro lado durante la visita de Estado, Donald Trump manejó de una manera muy distinta los temas de seguridad y de comercio; durante la conferencia de prensa con su homólogo Moon Jae-in en Cheong Wa-dae (la Casa Azul), en Seúl, el 7 de noviembre, abordaron los temas económicos y militares de manera conjunta, ${ }^{9}$ como una forma de presionar al gobierno de Corea del Sur para acatar las demandas del gobierno Estados Unidos en torno a las cuestiones económicas; por otro lado, el mandatario estadounidense se refirió

\footnotetext{
${ }^{7}$ Donald Trump visitó Asia Pacífico por la cumbre 2017 del APEC y aprovechó para reafirmar las políticas de Estados Unidos en torno a la crisis norcoreana con actores claves dentro del conflicto, como fueron Japón, Corea del Sur y China.

${ }^{8}$ El acuerdo de libre comercio entre ambos países ha estado en renegociaciones durante mucho tiempo; el mercado estadounidense representa $14 \%$ de las exportaciones de Corea del Sur, por lo cual se podría considerar terminar el acuerdo sin generar una crisis económica.

${ }^{9}$ Es importante mencionar la venta de armas como uno de los principales ingresos de Estados Unidos; el aumento de las tensiones entre Corea del Sur y Corea del Norte podría ser, hasta cierto punto, benéfico para Estados Unidos. La intensificación de las tensiones garantiza un mercado en donde ubicar su armamento.
} 
a la calidad de las armas proporcionadas, asegurando que "no existían mejores" para salvaguardar la seguridad de Corea del Sur, creando de esta manera el escenario perfecto para reactivar su economía de guerra.

La presencia militar de Estados Unidos en la región de Asia ha perjudicado de una manera considerable los diálogos de paz entre las Coreas desde el cambio de administración estadounidense. Las políticas y las sanciones contra Corea del Norte han provocado una respuesta agresiva contra Corea del Sur, complicando los diálogos de paz y dejando de lado los mecanismos de solución pacífica de la controversia, para dar lugar a una política de disuasión con base en acuerdos de cooperación militar con los gobiernos de Estados Unidos y de Japón.

El cambio de administración estadounidense modificó radicalmente la política exterior surcoreana en torno a la crisis; el gobierno surcoreano, a pesar de la renegociación del Acuerdo de Libre Comercio y de la incertidumbre del apoyo estadounidense, ha cooperado de manera favorable con la nueva administración en materia de seguridad; desde la construcción de los sumergibles hasta el acuerdo de inteligencia firmado con el gobierno de Japón, los temas de seguridad de Corea de Sur parecen mantener armonía con las políticas de Estados Unidos en relación con la crisis en la región.

\section{El equilibrio de poder entre los actores regionales y la correspondencia en el ejercicio de sus políticas exteriores en relación con la crisis norcoreana}

En materia de política exterior, la relación entre los actores regionales y el ejercicio en torno a la crisis norcoreana es complicada por los efectos indirectos de las políticas exteriores; es decir, las acciones del gobierno de Estados Unidos contra el régimen de Kim Jong-un afectan la relación de éste con el gobierno surcoreano; a la vez que las relaciones del gobierno surcoreano con el gobierno de Estados Unidos afectan sus relaciones con el régimen de Pyongyang. Por lo tanto, el ejercicio de la política exterior de Estados Unidos en la región Asia Pacífico, y en particular la relación con Corea del Sur puede determinar el ejercicio de la política exterior surcoreana en torno a la crisis norcoreana. ${ }^{10}$

\footnotetext{
${ }^{10}$ Esta misma relación ocurre con Japón: el ejercicio de la política exterior del gobierno japonés actúa generalmente a favor del ejercicio de la política estadounidense (Yoon, 2011).
} 
El aumento de las tensiones y la injerencia militar de Estados Unidos en la región tuvieron repercusiones importantes en el ejercicio de la política exterior de Corea del Sur con China y Japón; como se ha mencionado con anterioridad, la firma del acuerdo de inteligencia con Japón fue una respuesta a las tensiones provocadas por la nueva administración de Estados Unidos, pues el comportamiento agresivo de ésta hacia Corea del Norte afecta directamente la seguridad regional.

Durante los primeros días del mes de noviembre de 2016, el gobierno chino condenó las acciones militares contra Corea del Norte; con esta acción, se posicionó en el escenario como un mediador en el conflicto (REUTERS Staff, 2016). El gobierno de la República Popular China trató de disuadir en diferentes ocasiones a los gobiernos de Estados Unidos, Corea del Sur y Japón de continuar con las maniobras militares y con las sanciones contra Corea del Norte, esperando reducir las tensiones en la península, retomar los diálogos de paz y evitar la presencia militar de Estados Unidos cerca de sus fronteras.

China es un actor clave en la región y uno de los aliados más importantes de Corea del Norte, por lo cual, el proyecto de los sumergibles y la firma del acuerdo de inteligencia con Japón tuvieron una fuerte repercusión en las relaciones diplomáticas de China; el Ministerio de Asuntos Exteriores condenó cualquier tipo de maniobra militar contra Corea del Norte para evitar que crezcan las tensiones. La firma del acuerdo de inteligencia representa un problema para China; las movilizaciones militares conjuntas entre Japón, Corea del Sur y Estados Unidos aumentarán la presencia militar estadounidense en la zona de influencia China (REUTERs Staff, 2016).

Las acciones de China, en el tenor de la crisis norcoreana, dieron un giro dramático a principios de 2017, al distanciarse del gobierno norcoreano; éste expresó su descontento con la República Popular China, después del lanzamiento de un misil balístico a principios del mes de febrero (Berlinger, 2017); el impacto del mismo en el mar territorial de Japón causó un aumento considerable en las tensiones en la región; el gobierno japonés calificó el ataque como intolerable, pero no respondió a la provocación del gobierno norcoreano. Los gobiernos de Estados Unidos y de Corea del Sur se sumaron rápidamente al de Japón para reprochar el ataque; debido a la presión de la comunidad internacional ejercida en Naciones Unidas (UN News Centre, 2017), el gobierno de China se sumó a la condena de estas acciones; el gobierno 
norcoreano realizó declaraciones contra China "por actuar según los intereses estadounidenses"; el gobierno chino no respondió a las agresiones y sólo unos meses después incentivó a Estados Unidos a reducir las tensiones, después del envío de un portaaviones a la península de Corea (Hunt, 2017).

Aunque las relaciones diplomáticas entre China y Corea del Norte han tenido altibajos a lo largo de 2017, el gobierno chino ha mantenido su papel como mediador del conflicto cuando aumentan las tensiones. A finales del mes de agosto el gobierno norcoreano lanzo un misil sobre Japón, lo que provocó una escalada en el conflicto; el gobierno de Japón reaccionó de manera inmediata, primero dijo estar preparado para futuras amenazas y, por otro lado, convocó a la comunidad internacional a sumar esfuerzos para imponer sanciones más duras y eficientes contra Corea del Norte, cuyo gobierno en varias ocasiones demostró ser impredecible y poco fiable (VT, 2017). El gobierno chino condenó al gobierno norcoreano por ignorar las resoluciones del Consejo de Seguridad, pero se negó a condenar el lanzamiento del misil; por otro lado, culpó a los gobiernos de Estados Unidos y de Corea del Sur por provocar a Pyongyang con las constantes movilizaciones militares en la región; el gobierno chino recalcó que este tipo de conductas dificulta los diálogos de paz (Sharman, 2017).

Las posturas de los gobiernos chino y japonés en torno a la crisis norcoreana son distintas; en el primero podemos observar un papel neutral entre los actores en conflicto, aunque en diferentes ocasiones ha cooperado de manera favorable con el gobierno estadounidense, siempre tiende a reducir las tensiones; el gobierno japonés tiene una posición muy marcada que va de la mano con el ejercicio de la política exterior de Corea del Sur y de Estados Unidos. ${ }^{11}$

La crisis norcoreana tiene como principales actores a Estados Unidos, las dos Coreas, Japón y China, y la interacción entre estos actores determina el ejercicio de las políticas exteriores de los mismos. Las intervenciones de China y de Estados Unidos (en administraciones republicanas) influyen de manera diferenciada en las relaciones intercoreanas; mientras el gobierno chino trata de reducir las tensiones para evitar la

\footnotetext{
${ }^{11}$ La presencia militar estadounidense en territorio japonés y el acuerdo de defensa mutua entre ambos hacen que el ejercicio de su política exterior en materia de seguridad esté coordinada.
} 
presencia militar de Estados Unidos en Asia Pacífico, el gobierno estadounidense tiende a aumentarlas, de esta manera, justifica su presencia militar en la región y mantiene activo un mercado en el cual ubicar su armamento, incentivando a los gobiernos de Corea del Sur y Japón a optar por una política basada en la disuasión por medio de la modernización de su armamento.

En el último día de las reuniones del foro APEC, Donald Trump criticó los tratados multilaterales con la región y aseguró: "los temas de seguridad económica son temas de seguridad nacional", como parte del endurecimiento de las políticas que busca poner en práctica para proteger el mercado interno (France 24, 2017). Mantener la crisis activa garantiza compradores de armamento y esto, a la vez, compensa las posibles pérdidas que pueda llegar a generar el término de un acuerdo de libre comercio para Estados Unidos.

La presión que ejerció en materia económica y de seguridad sobre el gobierno de Corea dejó en claro, en materia económica, la poca participación del mercado estadounidense en las exportaciones e importaciones surcoreanas; en materia de seguridad, por otro lado, se observa una completa dependencia de Corea del Sur con respecto a Estados Unidos y es aquí donde la nueva administración ejerce presión; así, gracias al aumento en la crisis norcoreana, el gobierno de Estados Unidos se ha beneficiado vendiendo armamento a los gobiernos de Corea del Sur y de Japón. Estados Unidos parece ser el único actor beneficiado por la crisis, garantizando principalmente dos cosas: la presencia de armamento nuclear y un gran número de personal castrense en la región Asia-Pacífico, y un mercado para ubicar su armamento.

La presencia militar de Estados Unidos en Asia Pacífico, una de las zonas con mayor flujo económico en el mundo, y las últimas declaraciones de Donald Trump en la conferencia del foro APEC, plantean un nuevo escenario en materia de seguridad nacional, como expresó el mandatario: "seguridad económica es seguridad nacional" (France 24, 2017). La administración de Donald Trump está dando una gran importancia a los temas económicos y militares, el gobierno de Corea del Sur, en particular, ha sufrido el endurecimiento en ambas políticas, tanto en su relación con la administración estadounidense como con los actores regionales involucrados en el conflicto. Sin embargo, como veremos en la tercera parte, la economía coreana ha logrado limitar su dependencia comercial con respecto a la estadounidense, modificando radicalmente la ecuación de las relaciones comerciales 
bilaterales. Es posible que observemos una constante en las tensiones de la crisis norcoreana, hasta que Estados Unidos vea satisfechos sus intereses económicos, o que el equilibrio de poder y las acciones del gobierno de la República Popular China consigan reducir el aumento en las tensiones y, de esta manera, evitar que existan condiciones que propicien la presencia militar de Estados Unidos en la región.

\section{LAS VICISITUDES DE UNA ECONOMÍA AVANZADA}

Según el Banco Mundial (BM), en 2016, Corea ocupaba el décimo primer lugar en el ranking de países, de acuerdo con el tamaño del producto interno bruto. ${ }^{12}$ Dada esa importancia, la economía coreana influye directamente en la evolución de la economía mundial y ésta, a su vez, repercute sobre la dinámica de aquélla. Esa determinación mutua puede ser observada en el comportamiento de las tasas de crecimiento real de una y otra economías, contenidas en el cuadro 1. Podemos observar que:

- Las trayectorias de la tasa de crecimiento real (TCR) del producto interno bruto de Corea (TCR-C) y de la tasa de crecimiento real del producto interno bruto mundial (TCR-M) son similares. Tienden a disminuir de 2006 a 2009, durante la fase de gestación y de explosión de la crisis financiera global. En ambos casos la recuperación de 2010 fue remarcable, pero no pudo ser sostenida y las dos economías entraron en una fase de estancamiento, con una TCR-M oscilando entre 2.44 y $2.83 \%$ y una TCR-C variando entre 2.29 y 3.34\%, durante 2012-2016.

- Las TCR-C son permanentemente superiores a las TCR-M; sin embargo, el diferencial tiende a disminuir y hace pensar que la maduración de la economía coreana como una economía avanzada tiene como saldo tasas de crecimiento real tendientes a igualar las tasas de crecimiento real de la economía global. Dicho de otra manera, la economía coreana ha agotado, primero, una fase de crecimiento acelerado y, luego, una de crecimiento moderado, para entrar ahora en una etapa de crecimiento lento; en ese sentido, la economía coreana parece seguir la senda trazada por la japonesa.

12 World Bank, Data Catalog, Gross Domestic Product 2016, disponible en: <http://databank. worldbank.org/data/download/GDP.pdf $>$. 
CuAdro 1. Evolución del PIB mundial y de Corea del sur, 2006-2016

\begin{tabular}{|c|c|c|c|c|c|c|c|c|c|c|c|}
\hline & 2006 & 2007 & 2008 & 2009 & 2010 & 2011 & 2012 & 2013 & 2014 & 2015 & 2016 \\
\hline $\begin{array}{l}\text { Total } \\
\text { mundial* }\end{array}$ & 60562178 & 63139784 & 64288535 & 63172837 & 65906151 & 67986285 & 69644493 & 71455775 & 73478536 & 75487619 & 77327846 \\
\hline $\mathrm{TCR}^{* *}$ & 8.34 & 4.26 & 1.82 & -1.74 & 4.33 & 3.16 & 2.44 & 2.60 & 2.83 & 2.73 & 2.44 \\
\hline $\begin{array}{l}\text { Corea } \\
\text { del sur* }\end{array}$ & 941020 & 992432 & 1020510 & 1027730 & 1094499 & 1134795 & 1160809 & 1194429 & 1234340 & 1268781 & 1304659 \\
\hline $\mathrm{TCR}^{* *}$ & 9.30 & 5.46 & 2.83 & 0.71 & 6.50 & 3.68 & 2.29 & 2.90 & 3.34 & 2.79 & 2.83 \\
\hline
\end{tabular}

* En billones de dólares, en precios constantes de 2010

** Tasa de crecimiento real

FUENTE: Elaboración propia, con información de Banco Mundial, Data Catalog, < https://data.worldbank.org/ indicator/NY.GDP. MKTP.KD>.

Por otra parte, en la gráfica 4 es observable el cambio estructural del PIB durante 19802017. Mientras el sector de los servicios ha mantenido una participación que oscila grosso modo alrededor de $60 \%$, el sector de las manufacturas la ha incrementado constantemente, pasando de 16.38 a $31.99 \%$. La estrategia gubernamental, basada en la promoción de la producción y exportación de manufacturas (Kim, 1985), estuvo acompañada de la urbanización acelerada de la población y, en consecuencia, el sector de electricidad, gas y agua también incrementó su participación en el PIB, de 0.83 a $2.17 \%$. Esa estrategia tuvo como contraparte la pérdida relativa de relevancia de los sectores económicos restantes; así, la contribución de la construcción se redujo del 12.11 a 5.09\%; la de la agricultura, de 8.96 a $2.02 \%$; la de minas y canteras, de 1.91 a 0.16 por ciento.

Los cambios estructurales en la configuración sectorial del PIB son preocupantes, cuando es considerado el comportamiento moroso de la economía global durante 2010-2017. En efecto, para una economía como la coreana, altamente dependiente de la demanda externa de bienes manufacturados, el crecimiento sostenido necesita una economía mundial dinámica y crecientemente abierta; sin embargo, después de la crisis financiera global de 2008-2009, la economía mundial se ha mantenido en una fase de crecimiento lento; si, además, es tomado en consideración el cambio de actitud de la administración Trump para proteger la economía estadounidense así como la posibilidad de que otros gobiernos también recurran al proteccionismo, es posible entender los problemas que enfrenta la economía coreana y que preocupan a los planificadores coreanos. 
GRÁFICA 4. Estructura sectorial del PIB, 1980-2017

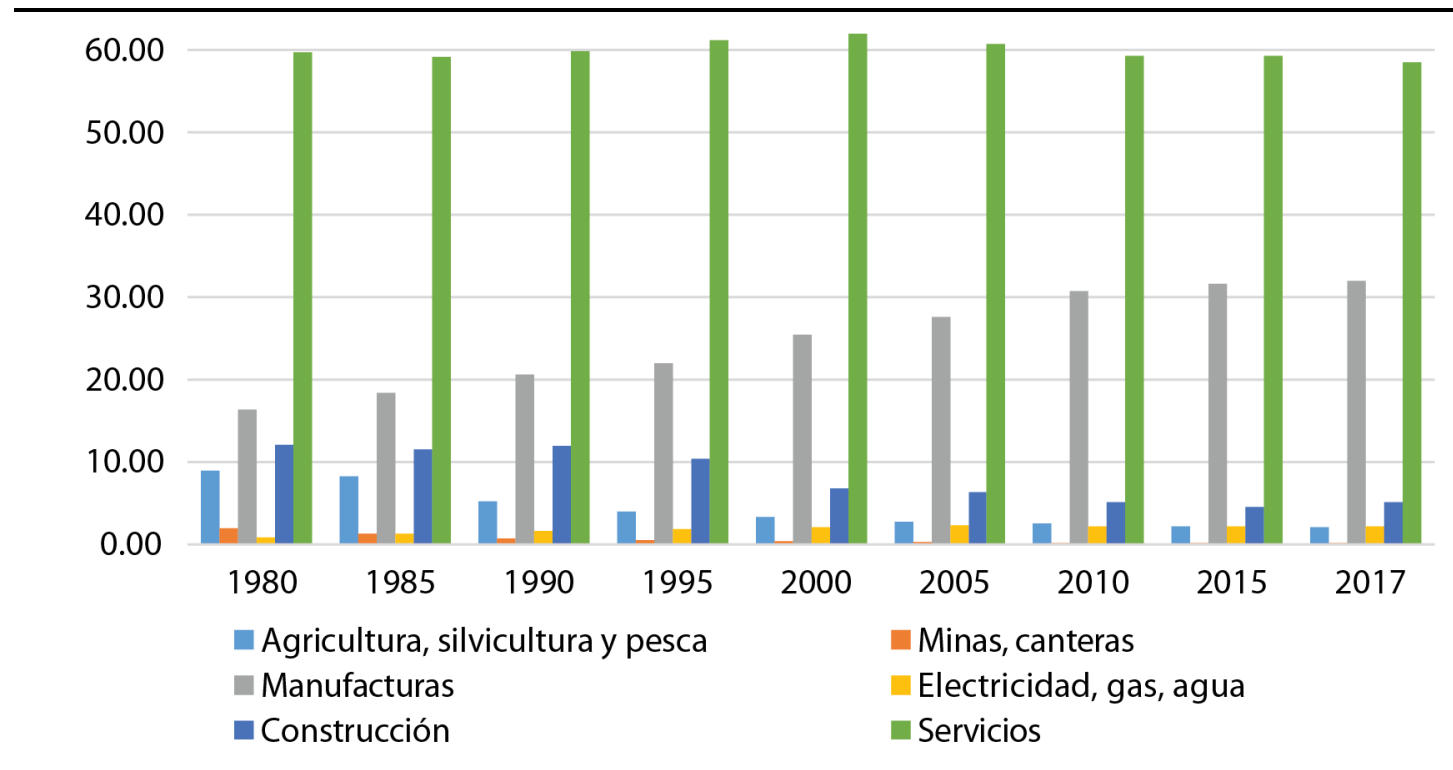

FUENTE: Elaboración propia, con información de Statistical Data Base, GDP and GNI by Economic Activities, <http://kosis.kr/eng/statisticsList/statisticsList_01List.jsp?vwcd=MT_ETITLE\&parentId=L\#SubCont> .

En primer término, la morosidad de la economía global ha tenido un efecto negativo sobre el sector manufacturero coreano; en el cuadro 2, resalta la tendencia hacia el mantenimiento de TCR sectoriales reducidas; además, si consideramos como parámetro las TCR de la economía coreana, es posible ver que las del sector manufacturas duplicaban el valor de aquéllas en 2010 y 2011, como consecuencia de la recuperación inmediata de la crisis financiera global. Durante 2012-2014, el diferencial siguió siendo positivo; sin embargo, las TCR de las manufacturas apenas superaban por algunas décimas las TCR del PIB coreano. Todavía más, durante 2015 y 2016, aquéllas fueron inferiores a las últimas, poniendo de realce la relación estrecha entre la morosidad de la economía global y la pérdida de dinamismo del sector manufacturero coreano. Finalmente, durante los doce meses que van de octubre de 2016 a septiembre de 2017, el sector manufacturero volvió a crecer con una tasa (4.22\%) superior a la del PIB coreano (2.85 por ciento).

En segundo lugar, el dinamismo decreciente del sector manufacturero ha sido, en parte, compensado por un dinamismo circunstancial de otros sectores económicos; el dinamismo es circunstancial en la medida en que no hay una tendencia específica derivada de una política gubernamental ad hoc. A lo sumo, podría decirse que durante 2015-2017, el sector de 
electricidad, gas, agua y, sobre todo, construcción, participaron en el crecimiento moderado de la economía coreana. Esto es importante, pues denota una voluntad gubernamental de compensar la disminución de la demanda externa con inversiones tendientes a activar la doméstica.

Otro efecto negativo de la morosidad de la economía global sobre la economía coreana ha quedado registrado en el desempeño del comercio internacional de Corea. Durante los doce meses que van del $1^{\circ}$ de octubre de 2015 al 30 de septiembre de 2016, el valor total de las exportaciones coreanas fue de 493082 millones de dólares ( $\mathrm{Md}$ ), perdiendo el equivalente a $9.43 \%$ del valor registrado durante los doce meses precedentes. Cierto, durante los doce meses posteriores, las exportaciones coreanas experimentaron una recuperación notable, para alcanzar un valor histórico de $562523 \mathrm{Md}$, equivalente a un incremento de $14.08 \%$ (cuadro 3 ).

La literatura especializada ha puesto de realce el desplazamiento de Estados Unidos por China como principal mercado para las exportaciones coreanas. En este trabajo, preferimos destacar el lugar de, por ejemplo, Vietnam, Singapur y Taiwán como mercados para las exportaciones coreanas. Vietnam durante el período 1 de octubre de 2016-30 de septiembre de 2017, devino el tercer socio comercial, con una tasa de absorción de las exportaciones coreanas de 7.91\%; Taiwán y Singapur sufrieron desplazamientos al octavo y noveno lugares, con tasas de absorción de 2.65 y $2.12 \%$, respectivamente.

En ese sentido y dado el progreso realizado por los procesos de integración económica en la región del Pacífico, preferimos destacar la función de los mercados regionales para las exportaciones coreanas. Así, el cuadro 3 resume la participación de los países que ocupan los 25 primeros lugares como destino de las exportaciones coreanas; ésos, en conjunto y durante los últimos 36 meses, han absorbido alrededor de $85 \%$ del valor total de las exportaciones de Corea.

El primer aspecto destacado es que 15 de esos países son asiáticos y, durante octubre de 2016-septiembre de 2017, concentraron 59.88\% del valor de las exportaciones; por subregiones asiáticas: Asia del Este detenta una tasa de absorción de 38.20\%; le siguen Asia del Sureste, con una tasa de $15.95 \%$, y otros países de Asia, con 5.73 por ciento. 
CUADRO 2. Tasas de crecimiento real* anuales y trimestrales del PIB, 2010-2017

\begin{tabular}{|c|c|c|c|c|c|c|c|c|c|c|c|c|c|c|c|c|}
\hline & \multirow[b]{2}{*}{2010} & \multirow[b]{2}{*}{2011} & \multirow[b]{2}{*}{2012} & \multirow[b]{2}{*}{2013} & \multirow[b]{2}{*}{2014} & \multirow[b]{2}{*}{2015} & \multirow[b]{2}{*}{2016} & \multirow[b]{2}{*}{$\begin{array}{c}2017 * \\
*\end{array}$} & \multirow{2}{*}{$\begin{array}{l}2015 \\
4 \mathrm{Tr}\end{array}$} & \multicolumn{4}{|c|}{2016} & \multicolumn{3}{|c|}{2017} \\
\hline & & & & & & & & & & $\begin{array}{c}\text { Ier. } \\
T r\end{array}$ & $\begin{array}{c}2 d o . \\
T r\end{array}$ & $\begin{array}{c}3 e r . \\
T r\end{array}$ & 4. $T r$ & $\begin{array}{l}\text { Ier. } \\
\text { Tr }\end{array}$ & $\begin{array}{c}2 d o . \\
T r\end{array}$ & $\begin{array}{l}3 e r \\
T r\end{array}$ \\
\hline PIB & 6.38 & 3.52 & 2.36 & 3.04 & 3.25 & 2.57 & 2.60 & 2.85 & 0.58 & 0.62 & 0.63 & 0.41 & 0.64 & 1.16 & 0.35 & 1.42 \\
\hline $\begin{array}{l}\text { Agricultura, } \\
\text { silvicultura, pesca }\end{array}$ & -4.32 & -1.95 & -0.86 & 3.09 & 3.60 & -0.43 & -2.86 & $\begin{array}{c}- \\
2.50\end{array}$ & -1.98 & 3.70 & -4.51 & -1.95 & -1.78 & 5.93 & -1.06 & -6.49 \\
\hline Minas, canteras & -8.33 & -1.04 & -0.27 & 8.14 & -0.11 & -1.28 & 1.63 & $\begin{array}{c}- \\
1.49\end{array}$ & -4.32 & 1.69 & -3.86 & 11.80 & -6.96 & -0.45 & 0.62 & -3.94 \\
\hline Manufacturas & 13.66 & 6.54 & 2.37 & 3.58 & 3.54 & 1.76 & 2.29 & 4.22 & 0.41 & 0.41 & 0.95 & -0.38 & 1.77 & 2.08 & -0.28 & 2.74 \\
\hline $\begin{array}{l}\text { Electricidad, gas, } \\
\text { agua }\end{array}$ & 5.87 & 0.21 & 3.98 & -0.30 & 2.62 & 5.10 & 3.59 & 1.19 & 0.57 & 0.07 & -0.01 & 3.40 & -3.02 & -1.37 & 3.79 & 3.53 \\
\hline Construcción & -3.69 & -5.46 & -1.81 & 2.96 & 0.76 & 5.70 & 10.53 & 9.11 & 0.88 & 3.56 & 2.65 & 2.32 & 1.31 & 5.32 & -1.34 & 1.31 \\
\hline Servicios & 4.41 & 3.09 & 2.76 & 2.86 & 3.30 & 2.81 & 2.33 & 1.88 & 0.75 & 0.40 & 0.53 & 0.61 & 0.24 & 0.25 & 0.78 & 0.94 \\
\hline
\end{tabular}

* Basadas en precios de 2010 .

** Calculadas sobre la base del 4o trimestre de 2016 y los tres primeros de 2017.

FUENTE: Elaboración propia, con información de KOSIS, Statistical Database, GDP and GNI by Economic Activities (Seasonally Adjusted, Chained 2010 Year Prices, Quarterly), <http://kosis.kr/eng/statisticsList/statistics List_01List.jsp?vwed=MT_ETITLE\&parentId=L\#SubCont $>$.

El segundo hecho relevante es el lugar (tercero) ocupado por América del Norte; en efecto, pese a que Estados Unidos es el segundo mercado de destino, la tasa conjunta de absorción de los tres países participantes en el Acuerdo de Libre Comercio de América del Norte (ALCAN) fue de 15.12\%; nótese: esta proporción es inferior a la correspondiente a Asia del Sureste. Es necesario esperar para ver si se trata de una situación coyuntural o de un cambio estructural que socava la influencia económica de Estados Unidos en la región del Pacífico Asiático. En todo caso, como vimos en la segunda parte, la erosión de la influencia estadounidense ha permitido a los responsables comerciales de Corea responder a las amenazas de la administración Trump en torno a una tercera negociación del Acuerdo de Libre Comercio Estados Unidos de América-República de Corea (ALC EUA-RC), con el anuncio de la disposición coreana para denunciar simple y llanamente el acuerdo comercial bilateral.

El tercer suceso notorio es la carencia de relevancia para Corea, tanto de Europa, como de Oceanía y otras regiones del mundo, como mercados regionales de exportación. En consecuencia, Asia, en general, y Asia del Pacífico, en particular, son ahora estratégicas para el desarrollo de la economía coreana. En este nuevo contexto, las veleidades proteccionistas de la administración Trump tendrán un efecto limitado sobre el comercio exterior coreano, como será visto más adelante. Por ahora, es necesario volver sobre la relevancia de los productos del sector "Maquinaria y equipo de transporte" en el valor de las exportaciones totales, pues se trata del 
sector más importante: concentra alrededor de 58\% de dicho valor (cuadro 4) e indica la alta dependencia de la demanda externa de productos del sector por parte de la economía coreana.

CUADRO 3. Exportaciones por países de destino, octubre de 2014-septiembre de 2017

\begin{tabular}{|c|c|c|c|c|c|c|c|c|c|}
\hline & \multicolumn{3}{|c|}{$\begin{array}{l}1 \text { oct. } 2014 \text { a } \\
30 \text { sep. } 2015 \text {. }\end{array}$} & \multicolumn{3}{|c|}{$\begin{array}{l}1 \text { oct. } 2015 \text { a } \\
30 \text { sep. } 2016 .\end{array}$} & \multicolumn{3}{|c|}{$\begin{array}{l}1 \text { oct. } 2016 \text { a } \\
30 \text { sep. } 2017\end{array}$} \\
\hline Total & & 544437 & & & 493082 & & & 562523 & \\
\hline Subtotal & & 460086 & 84.51 & & 419814 & 85.14 & & 486494 & 86.48 \\
\hline Asia del Este & & 210508 & 38.67 & & 192150 & 38.97 & & 214886 & 38.20 \\
\hline China & 1 & 141253 & 25.94 & 1 & 124752 & 25.30 & 1 & 136459 & 24.26 \\
\hline Hong Kong & 3 & 29400 & 5.40 & 3 & 31935 & 6.48 & 4 & 36898 & 6.56 \\
\hline Japón & 5 & 27136 & 4.98 & 5 & 23975 & 4.86 & 5 & 26598 & 4.73 \\
\hline Taiwán & 7 & 12719 & 2.34 & 8 & 11488 & 2.33 & 8 & 14932 & 2.65 \\
\hline Asia del Sureste & & 74820 & 13.74 & & 70842 & 14.37 & & 89714 & 15.95 \\
\hline Vietnam & 4 & 27167 & 4.99 & 4 & 30327 & 6.15 & 3 & 44511 & 7.91 \\
\hline Singapur & 6 & 15455 & 2.84 & 6 & 12821 & 2.60 & 9 & 11938 & 2.12 \\
\hline Filipinas & 13 & 8714 & 1.60 & 14 & 7160 & 1.45 & 11 & 9774 & 1.74 \\
\hline Malasia & 14 & 7623 & 1.40 & 13 & 7612 & 1.54 & 14 & 8153 & 1.45 \\
\hline Indonesia & 12 & 9099 & 1.67 & 15 & 6639 & 1.35 & 15 & 8009 & 1.42 \\
\hline Tailandia & 16 & 6760 & 1.24 & 17 & 6282 & 1.27 & 16 & 7329 & 1.30 \\
\hline Asia otros & & 38798 & 7.13 & & 29255 & 5.93 & & 32232 & 5.73 \\
\hline India & 8 & 12136 & 2.23 & 7 & 11648 & 2.36 & 7 & 14988 & 2.66 \\
\hline Emiratos Árabes & 18 & 6478 & 1.19 & 20 & 5374 & 1.09 & 19 & 6188 & 1.10 \\
\hline Turquía & 19 & 6396 & 1.17 & 19 & 5724 & 1.16 & 20 & 5905 & 1.05 \\
\hline Arabia Saudita & 11 & 9668 & 1.78 & 16 & 6510 & 1.32 & 22 & 5151 & 0.92 \\
\hline Irán & 25 & 4120 & 0.76 & & & & & & \\
\hline América del Norte & & 88424 & 16.24 & & 81033 & 16.43 & & 85079 & 15.12 \\
\hline EEUU & 2 & 71761 & 13.18 & 2 & 67010 & 13.59 & 2 & 69074 & 12.28 \\
\hline México & 9 & 11913 & 2.19 & 9 & 9186 & 1.86 & 10 & 11186 & 1.99 \\
\hline Canadá & 24 & 4750 & 0.87 & 21 & 4837 & 0.98 & 24 & 4818 & 0.86 \\
\hline Europa & & 22118 & 4.06 & & 26008 & 5.27 & & 32976 & 5.86 \\
\hline Reino Unido & 21 & 5570 & 1.02 & 11 & 7741 & 1.57 & 12 & 8564 & 1.52 \\
\hline Alemania & 20 & 6304 & 1.16 & 18 & 6209 & 1.26 & 13 & 8265 & 1.47 \\
\hline Rusia & 22 & 5314 & 0.98 & 22 & 4619 & 0.94 & 18 & 6727 & 1.20 \\
\hline Noruega & 23 & 4930 & 0.91 & 25 & 3631 & 0.74 & 23 & 4840 & 0.86 \\
\hline Países Bajos & & 0 & & 24 & 3807 & 0.77 & 25 & 4579 & 0.81 \\
\hline Oceanía & & 18761 & 3.45 & & 16338 & 3.31 & & 26254 & 4.67 \\
\hline Australia & 10 & 11286 & 2.07 & 12 & 7693 & 1.56 & 6 & 19262 & 3.42 \\
\hline Islas Marshall & 15 & 7476 & 1.37 & 10 & 8646 & 1.75 & 17 & 6992 & 1.24 \\
\hline Brasil & 17 & 6656 & 1.22 & 23 & 4187 & 0.85 & 21 & 5354 & 0.95 \\
\hline
\end{tabular}

* Millones de dólares.

FUENTE: Elaboración propia, con información de KOSIS, Statistical Database, National Accounts, Trade by Countries, http://kosis.kr/eng/statisticsList/statisticsList_01List.jsp?vwcd=MT_ETITLE\&parentId=L\#SubCont. 
Ahora bien, durante la contracción de las exportaciones registrada durante 2015-2016, siete de las nueve clasificaciones sectoriales registraron tasas negativas de crecimiento y todas ellas fueron inferiores a $-9.43 \%$ promedio de las exportaciones totales. En el caso del rubro "Maquinaria y equipo de transporte", la tasa fue de $-10.72 \%$. Durante 2016-2017, la recuperación de las exportaciones tuvo como saldo una tasa general de crecimiento de $14.08 \%$; los nueve rubros clasificatorios también registraron tasas positivas y, en el caso del sector "Maquinaria y equipo de transporte", la proporción fue de un robusto 16.75 por ciento.

CUADRO 4. Principales indicadores de las exportaciones totales y sectoriales, 2015-2017



FUENTE: Elaboración propia, con información de KOsIs, Statistical Database, National Accounts, Trade by Goods. $<$ http://kosis.kr/eng/statisticsList/statisticsList_01List.jsp? vwcd=MT_ETITLE\&parentId=L\#SubCont>.

El cuadro 5 contiene la información desagregada de los subsectores correspondientes a las exportaciones de "Maquinaria y equipo de transporte", de acuerdo con la clasificación utilizada por el gobierno coreano. Un aspecto importante es que los vehículos de transporte 
están clasificados en dos subsectores diferentes: "Vehículos para carretera" y "Otros equipos de transporte"; en conjunto, ambos concentran alrededor de $25 \%$ del valor de las exportaciones sectoriales. Por otra parte, Los subsectores "Máquinas y aparatos eléctricos, electrodomésticos y refacciones", "Aparatos, equipos y refacciones para telecomunicaciones y para grabar y reproducir sonido" y "Máquinas de oficina y para procesar datos", en conjunto, concentran alrededor de 50\% del valor de las exportaciones sectoriales.

CUADRO 5. Principales indicadores de las exportaciones de maquinaria y equipo de transporte, 2015-2017

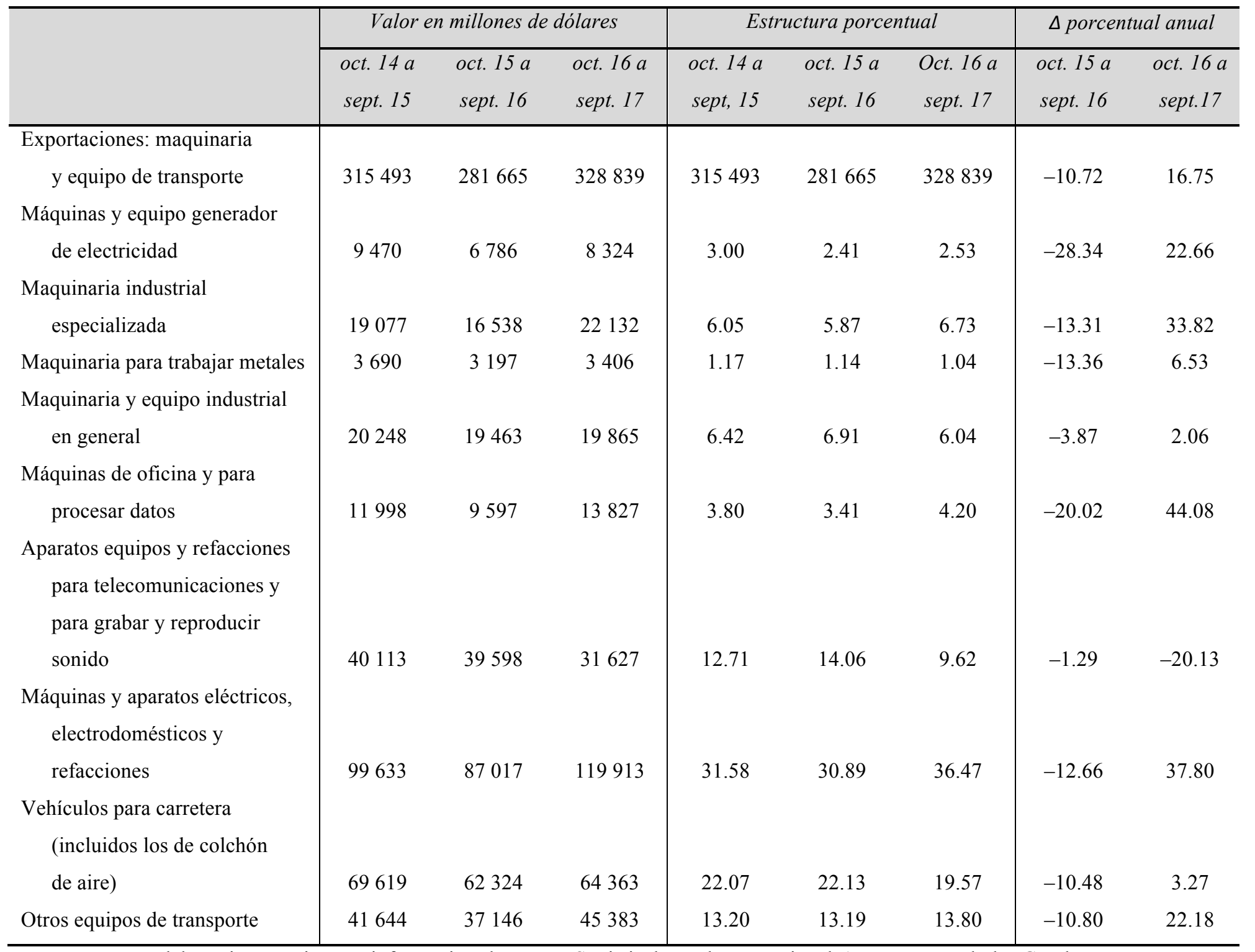

FUENTE: Elaboración propia, con información de KOSIS, Statistical Database, National Accounts, Trade by Goods, $<\mathrm{http} / / / \mathrm{kosis} . \mathrm{kr} / \mathrm{eng} /$ statisticsList/statisticsList_01List.jsp?vwcd=MT_ETITLE\&parentId=L\#SubCont>. 
La clasificación coreana dificulta la comparación con las informaciones estadísticas de otras bases de datos; sin embargo, es notorio que, para la economía de Corea, las exportaciones de máquinas y equipos eléctricos, equipos de telecomunicaciones y grabadoras-reproductoras de sonido, así como máquinas de oficina y de cómputo, son más importantes que las exportaciones de equipos de transporte. Ahora bien, todos esos productos manufacturados son altamente sensibles a las variaciones de la demanda externa, como lo demuestran las tasas negativas de crecimiento registradas por todos los subsectores durante 2015-2016 y las elevadas tasas positivas registradas cuando menos por cinco subsectores durante 2016-2017. Durante esta recuperación, el hecho notable es la tasa de crecimiento de $3.27 \%$ obtenida por el subsector "Vehículos para carretera", la cual indica las dificultades del sector en la economía global y, como será visto ahora, en el mercado de América del Norte.

El cuadro 6 ha sido construido con información proveniente de otra base de datos; en consecuencia, las clasificaciones de los bienes de exportación son diferentes a las utilizadas por las autoridades coreanas; pese a ello, es posible destacar algunos hechos notables.

En primer término, resalta el lugar terciario ocupado por el mercado de América del Norte como destino de las exportaciones coreanas. Durante el lapso de octubre de 2014 a septiembre de 2017, América del Norte absorbió alrededor de 16\% de ellas. Esta proporción, por sí misma, indica que, en términos generales, la renuncia coreana al ALC EUA-RC, o el establecimiento de reglas de origen regionales más drásticas en el marco del ALCAN, tendrán un efecto mitigado sobre el conjunto de la economía coreana.

Sin embargo, en términos sectoriales particulares, el escenario es de alto riesgo, sobre todo para el sector coreano de la industria del automóvil. En efecto, el sector "87. Vehículos que no sean tranvías o material rodante ferroviario, partes y accesorios" del Harmonized System (HS), utilizado por el International Trade Centre, equivale grosso modo al sector "Vehículos para carretera" usado por las autoridades coreanas. En el cuadro 6, podemos observar que el sector concentra, más o menos, $12 \%$ del valor total de las exportaciones coreanas y que ocupa el tercer lugar dentro de la clasificación HS; esta proporción permite afirmar que el impacto de las restricciones comerciales en Estados Unidos o en el ALCAN será mitigado para el conjunto de la economía coreana. Sin embargo, en el cuadro 6, también 
podemos observar que alrededor de $41 \%$ del valor de las exportaciones sectoriales está concentrado en el mercado del ALCAN; por lo tanto, las consecuencias de un cambio de régimen comercial en la región tendrá repercusiones importantes para el sector coreano de la industria del automóvil.

El sector "85. Maquinaria y equipos eléctricos, grabadoras y reproductores de sonido, televisores" del HS se encuentra en una situación opuesta. Por un lado, es el más importante en la estructura de las exportaciones coreanas, en la medida en que aporta alrededor de $26 \%$ del valor total de las exportaciones coreanas; por el otro, el área del ALCAN tan sólo absorbe $11 \%$ de las exportaciones sectoriales; esta proporción permite sustituir los mercados de América del Norte con los de otras regiones del continente americano o del planeta.

CuAdro 6. Participación de América del Norte en las exportaciones totales y sectoriales de Corea

\begin{tabular}{l|ccc|}
\hline & oct. 14 a & oct. 15 a & oct. 16 a \\
& sept. 15 & sept. 16 & sept. 17 \\
\hline A. Exportaciones totales* & 544854 & 493233 & 562958 \\
$\quad$ Con destino a América del Norte & 88796 & 81320 & 85422 \\
Como \% de A & 16.30 & 16.49 & 15.17 \\
85. Maquinaria y equipos eléctricos y sus partes; grabadoras & 139851 & 133398 & 153818 \\
y reproductores de sonido, televisores* & & & \\
Como \% de A & 25.67 & 27.05 & 27.32 \\
$\quad$ A América del Norte* & 14963 & 16192 & 14828 \\
Como \% de 85 & 10.70 & 12.14 & 9.64 \\
84. Maquinaria, aparatos mecánicos, reactores nucleares, & 63750 & 57351 & 67846 \\
calderas; sus partes* & & & \\
Como \% de A & 11.70 & 11.63 & 12.05 \\
Con destino a América del Norte* & 15553 & 13323 & 16321 \\
Como \% de 84 & 24.40 & 23.23 & 24.06 \\
87. Vehículos que no sean tranvías o material rodante & 70173 & 63159 & 64917 \\
ferroviario, y sus partes y accesorios* & & & \\
Como \% de A & 12.88 & 12.80 & 11.53 \\
Con destino a América del Norte* & 27399 & 26547 & 26090 \\
Como \% de 87 & 39.04 & 42.03 & 40.19 \\
\hline
\end{tabular}

* Millones de dólares.

FUENTE: Elaboración propia, con información de Internacional Trade Center, Trademap, $<$ http://www.trademap.org/Bilateral_MQ_TS.aspx?nvpm=1|410||14|TOTAL||2|1|1|2|2|2|1|1|1>. 
Finalmente, el sector "84. Maquinaria, aparatos mecánicos, reactores nucleares, calderas" tiene la particularidad de estar vinculado a los dos sectores precedentes; esto se debe a que incluye tanto maquinaria y equipo para la generación de electricidad como motores de combustión interna; los efectos negativos de nuevas barreras comerciales en América del Norte serán menores para aquellos subsectores vinculados al sector 85, pero mayores para los relacionados con el 87.

En resumen, la vinculación de los temas comerciales con los de seguridad regional establecida por la administración Trump es bivalente. En el plano de la relación bilateral Corea-Estados Unidos, corre el riesgo de quedarse en retórica pura, en la medida en que la economía coreana ha logrado limitar el grado de dependencia comercial con respecto a la estadounidense. De ahí que las autoridades coreanas no duden en adelantarse a sus contrapartes estadounidenses para desechar el acuerdo comercial bilateral.

En el plano de la influencia estadounidense en la región asiática del Pacífico, la consolidación de las vinculaciones económicas entre las economías de Asia del Este, así como entre éstas y las de Asia del Sureste, puede abrir un nuevo frente para las intervenciones estadounidenses; la justificación de esas nuevas intervenciones en el plano económico sería justificada con el argumento según el cual un bloque económico asiático del Pacífico representa una amenaza para la seguridad estadounidense.

El contexto regional marcado por las tensiones derivadas de la crisis norcoreana y el marco global subvertido por el discurso agresivo de Donald Trump, pese a todo, no han impedido que la sociedad coreana haya emprendido un proceso de limpieza institucional; es de esperar que la democratización del sistema político coreano se consolide y que pueda influir en la superación de los obstáculos políticos tendientes a limitar la integración de Asia del Pacífico. 


\section{BIBLIOGRAFÍA}

Barry, M. P., "The U.S. and the 1945 Division of Korea: Mismanaging o the 'Big Decisions"”, International Journal on World Peace, vol. 29, núm. 4, 4 de diciembre de 2012.

BBC Mundo, “Corea del Norte 'lanza sin éxito’ un misil desde su costa este, según Corea del Sur y Estados Unidos", $B B C, 16$ de abril de 2017.

Berlinger, J., “China, Russia condemn North Korea's missile launch”, $C N N, 13$ de febrero de 2017.

Boxall, Andy, "Samsung Chairman Guilty of Corruption, Sentenced to Five Years in Jail", Digital Trends, 25 de agosto de 2017. Disponible en: <https://www.digitaltrends. com/mobile/samsung-group-offices-raided-korea-political-scandal-news/.

Boykoff, J. G., “Donald Trump ahora amenaza a Corea del Sur”, Expansión, 28 de abril de 2017.

El Mundo, “Estados Unidos seguirá apoyando a Corea del Sur”, El Mundo, 10 de noviembre de 2016.

El Mundo, "Corea del Norte amenaza con 'medidas duras de autodefensa' ante las nuevas sanciones de la ONU”, El Mundo, 2 de diciembre de 2106.

Fendos, Justin, “The History of a Scandal: How South Korea's President was Impeached”, The Diplomat, 24 de febrero de 2017. Disponible en: <https://thediplomat.com/ 2017/01/the-history-of-a-scandal-how-south-koreas-president-was-impeached/>.

Fernández Liesa, Carlos R. y E. Borque Lafuente, El conflicto de Corea, Madrid, Ministerio de Defensa, 2013.

Fifield, Anna, "Samsung Scion to be Indicted on Bribery Charges", The Washington Post, 28 de febrero de 2017. Disponible en: <https://www.washingtonpost.com/world/ samsung-scion-to-be-indicted-on-bribery-charges/2017/02/28/b5988fca-863c-4ca78b7d-9e105549d9a9_story.html?utm_term=.f8663aa4a88f.>

G. M., Brevario de ideas políticas, Colombia, 1991. 
Government of Korea, The Constitution of the Republic of Korea, Seúl, Corea, 26 de octubre de 1987.

Hunt, K., "China llama a la calma después de que EE.UU. enviara un portaaviones a la Península de Corea", CNN, 12 de abril de 2017.

Kim, Kwan S., "The Korean Miracle (1962-1980) Revisited: Myths and Realities in Strategy and Development", Kellogg Institute, Working Paper \# 166, 1991. Disponible en: $<$ https://kellogg.nd.edu/sites/default/files/old_files/documents/166_0.pdf $>$.

Lee, R., "Did Japanese fighter jets really participate in a military drill in Korean territory? Or were they only escorts outside Korean territory?", The Korea Times, 3 de noviembre de 2017.

León-Manríquez, José Luis y Cintli A. Cárdenas Barajas, “¿Hell Choson o Paraíso de los Unicornios? Corea del sur en 2016", Anuario Asia-Pacifico 2017, México, El Colegio de México, 2017. Disponible en: $<$ http://anuarioasiapacifico.colmex.mx/images/pdfs/ 07corealeoncardenas.pdf $>$.

Leung, Janice, "The South Korea Rasputin", The London Globalist, 12 de noviembre de 2016. Disponible en: $<\mathrm{http}: / / \mathrm{www}$.thelondonglobalist.org/2527-2/>.

REUTERS Staff, "Japan, South Korea sign preliminary intelligence-sharing pact on North Korea", REUTERS, 14 de noviembre de 2017.

REUTERS Staff, "China condemns South Korea's warning shots at its fishing vessels", REUTERS, 2 de noviembre de 2016.

RT, "Corea del Sur se lanza a la construcción de nuevos submarinos con misiles balísticos", $R T, 14$ de diciembre de 2016.

Sharman, J., "North Korea missile over Japan: China blames US and South Korea for provoking Pyongyang", Independent, 29 de agosto de 2017.

UN News Centre, “UN strongly condemns DPR Korea's ballistic missile launch”, UN News, 13 de febrero de 2017. 
Villar, M., "El Consejo de Seguridad condena el ensayo norcoreano y EEUU reclama acciones", Agencia EFE, 14 de febrero de 2017.

VT, “Japanese react furiously to North Korean missile launch", DW, 30 de agosto de 2017.

Whan-Woo, Y., "Envoy hopes for Russia's expanded role with North Korea”, The Korean Times, 4 de noviembre de 2017.

Wikipedia, "Choi Tae-min". Disponible en: <https://en.wikipedia.org/wiki/Choi_Tae-min>.

Wikipedia, "Elections in South Korea". Disponible en: < <ttps://en.wikipedia.org/wiki /Elections_in_South_Korea>.

Wikipedia, "Impeachment of Park Geun-hye". Disponible en: <https://en.wikipedia.org/ wiki/Impeachment_of_Park_Geun-hye >.

Wikipedia, "Park Chung-hee". Disponible en: <https://en.wikipedia.org/wiki/Park_Chunghee>.

YonHap News Agency, "Corea del Sur y EE. UU. acelerarán las renegociaciones del TLC", YonHap.

YonHap News Agency, "Trade minister requests authority to end FTA with U.S., augmentation of negotiation team: source", YonHap News Agency, 2 de noviembre de 2017.

Yoon, J.-H., "The Effect of US Foreign Policy on the Relationship between South and North Korea: Time Series Analysis of the Post-Cold War Era”, Journal of East Asian Studies, 2011. 